\title{
RBEP
}

\section{Ética na visão de mundo de alunos do ensino fundamental: o caso de uma escola pública municipal ${ }^{*}$}

Renato José de Oliveira

Andrea Penteado de Menezes

Cristina Nacif Alves

Daniela Patti do Amaral

\section{Resumo}

Retrata estudo de caso feito em uma escola pública municipal, no Rio de Janeiro, a respeito da visão de ética dos alunos de oitavo e nono anos. O objetivo foi traçar um perfil que sirva de orientação para investigações posteriores que tenham como objeto o trabalho com a ética no ensino fundamental. O estudo foi balizado pelas contribuições teórico-metodológicas de Perelman e Olbrechts-Tyteca, complementadas pelos aportes de Meyer, autores do campo da argumentação. A principal conclusão é a de que, entre os sujeitos pesquisados, a heteronomia predomina sobre a autonomia, sugerindo que a visão de ética assume um perfil conservador.

Palavras-chave: visão de ética; ensino fundamental; argumentação; heteronomia.

\footnotetext{
* Estudo conduzido com base em pesquisa realizada entre os anos de 2007 e 2010, que envolveu três escolas de ensino fundamental do município do Rio de Janeiro, a qual contou com o apoio do Conselho Nacional de Desenvolvimento Científico e Tecnológico (CNPq)
} 


\section{Abstract \\ Ethics in the world view of elementary school students: the case of a public school}

This paper focuses the case study done in a public school in Rio de Janeiro on the ethical view of students of the eighth and ninth grades of elementary school. The goal was to make a profile which serves as a guidance for further investigations whose purpose is to study ethics in the school. The research was based on the approach of Perelman and Olbrechts-Tyteca and supplemented by contributions from Meyer, who are authors of de field of argument. The main conclusion is that among the subjects studied heteronomy prevails on autonomy, suggesting that the view of ethics takes a conservative profile.

Keywords: ethical view; elementary school; argument; heteronomy.

\section{Introdução}

Desde meados dos anos 1990, a importância do trabalho com a ética na educação vem sendo destacada no cenário educacional brasileiro e internacional. O Relatório Delors (Unesco, 1996) ressaltou a importância de se valorizar a dimensão ética no contexto educativo, situando-a como capacidade de compreender o outro em suas especificidades e o mundo em um cenário de profundas mudanças tecnológicas, políticas, econômicas e sociais. Esse trabalho não significaria desenvolver um ensino sobre valores, pois "querer impor valores previamente definidos, pouco interiorizados, leva no fim das contas à sua negação, porque só têm sentido se forem livremente escolhidos pela pessoa" (Unesco, 1996, p. 59).

No Brasil, os Parâmetros Curriculares Nacionais (PCN) do ensino fundamental defenderam a inclusão da ética na escola como um tema transversal que deveria perpassar todas as disciplinas. A perspectiva era a de que a comunidade escolar se engajasse no trabalho efetivo com uma educação voltada para a cidadania, vista como "eixo vertebrador da educação escolar" (Brasil. MEC, 1998a, p. 23), visando à formação de alunos capazes de desenvolverem o pensamento crítico acerca dos problemas relativos à convivência social. Também as Diretrizes Curriculares Nacionais (DCN) para o ensino fundamental enfatizaram esses objetivos ao afirmarem que a escola deveria se pautar pelos "princípios éticos da autonomia, da responsabilidade, da solidariedade e do respeito ao bem comum" (Brasil. Mec, 1998b, p. 4). 
A partir daí, é oportuno situar o que compreendemos por ética/ moral, justificando por que não as diferenciamos, embora no curso do desenvolvimento do pensamento ocidental tenham surgido muitas distinções entre elas. Na visão kantiana, por exemplo, os conteúdos das regras de convivência humana (não matar, não mentir, etc.) são morais, já que se baseiam em crenças religiosas, humanistas, etc. Por sua vez, as razões para respeitá-las são éticas, porque se originam do trabalho de reflexão que compete à razão prática: em um mundo de assassinos, a sobrevivência de cada homem estaria sempre ameaçada. Assim, a legitimidade de um preceito como "não matar" não é dada pelas crenças (religiosas, políticas, etc.), que são contingentes, mas pela relação necessária que a razão prática extrai entre o princípio da ação e a própria ação. Por isso foram chamados por Kant de imperativos categóricos, dos quais é possível extrair a lei geral que governa a razão prática: "age de tal maneira que a máxima da tua vontade seja sempre ao mesmo tempo o princípio de uma legislação universal" (Kant, 1997, p. 42).

A abordagem kantiana tem sido objeto de diversas críticas, na medida em que não responde a uma série de problemas concretos da existência. Tugendhat (1997, p. 31) assinala que um sistema de princípios morais é sempre avaliado em relação a outro, sendo sua fundamentação algo relativo e não absoluto, como pretendia Kant.

Perelman e Olbrechts-Tyteca (2005) assinalam, por sua vez, que a avaliação é o julgamento feito pelo auditório ${ }^{1}$ a partir do embate argumentativo entre diferentes oradores, os quais formularão suas teses com base na reflexão sobre os princípios e sobre os juízos morais admitidos por esse mesmo auditório. A ética (ou moral) se coloca, então, como percurso de mão dupla entre os princípios e os juízos, isto é, se configura em processo dialético por meio do qual estes permitem conferir conteúdo concreto àqueles e também por meio do qual os próprios juízos recebem limites e são regulados pelos princípios gerais que permitem formar uma visão de conjunto mais ampla e menos dependente dos particularismos de natureza cultural, social, religiosa ou política.

Com base nas colocações perelmanianas, entendemos que a reflexão, o julgamento e as decisões não se constituem momentos particulares do sujeito ético, assim como as ações consideradas boas ou virtuosas não são prerrogativas do sujeito moral, pois ambos são compreendidos como indissociáveis. Em vista disso, tomamos ética e moral como termos intercambiáveis, que se referem aos mesmos objetos: valores, hierarquias de valores, princípios e hábitos que orientam as ações do homem no contexto de suas múltiplas relações. São construções históricas e intersubjetivas e, na medida em que não precisam necessariamente recorrer a uma norma transcendente, procuram o fundamento normativo "no espaço intramundano, no que é ordinário ou que representa a maioria dos casos, naquilo que é referendado pelo consenso da maioria" (Samaranch, 1991, p. 239). Tal acordo majoritário só é possível após o confronto entre diferentes pontos de vista por meio de práticas argumentativas e não por meio de ações impositivas.
${ }^{1}$ As categorias de orador e auditório serão discutidas no terceiro tópico. 
Feitas essas considerações e tendo como suporte o referencial de análise oferecido por Perelman e Olbrechts-Tyteca (2005) e Michel Meyer (1998), buscamos investigar, entre os anos de 2007 e 2010, a visão de ética dos alunos de três escolas de ensino fundamental do município do Rio de Janeiro, duas particulares, situadas na zona sul, e uma pública municipal, situada na zona norte, em bairro popular.

Em face das limitações de tamanho estabelecidas para o presente artigo, apresentaremos e discutiremos os resultados a que chegamos a partir da pesquisa feita na escola pública municipal, por meio de um questionário (Anexo 1) do qual trabalharemos as respostas dadas às questões 1 (tomada como central), 4, 4.1, 4.2, 4.3 e 4.4 (tomadas como complementares).

Os respondentes (oradores) foram estudantes de oitavo e nono anos, escolhidos por supormos que poderiam ter um nível de argumentação mais elaborado do que os alunos dos anos precedentes, levando-se em consideração a maior quantidade de anos escolares cursados.

Para subsidiar as análises, apresentamos um perfil baseado em informações colhidas na parte do questionário relativa a informações pessoais, preservando, naturalmente, o anonimato dos estudantes. Por se tratar de uma pesquisa exploratória, as conclusões apresentadas ao final se colocam como ponto de partida para investigações futuras, que venham a trabalhar com um número maior de escolas e que contemplem as diferentes regiões geográficas do município.

\section{A ética no contexto educacional brasileiro}

\section{a) O que dizem as pesquisas acadêmicas?}

Utilizando como ferramentas de busca as expressões exatas ética no ensino fundamental e ética na escola, fizemos um levantamento junto ao banco de teses e dissertações da Capes, compreendendo o período de 1987 a 2009. Foram localizados os resumos de apenas seis trabalhos, que passaremos a comentar brevemente.

Carvalho (2004) tomou por base os conceitos aristotélicos de felicidade, virtude, bem e prudência e investigou a visão de ética de professores do ensino fundamental, contudo não mencionou o quantitativo de sujeitos e de escolas que compuseram a amostra. A questão central que norteou a pesquisa visava levantar dados sobre como o professor trabalha com a ética em sua disciplina, e as principais conclusões apontaram para a existência de um comprometimento docente em relação a esse trabalho.

Rodrigues (2000) desenvolveu um estudo em que buscou, a partir da leitura de diversos autores (não mencionados), compreender os valores humanos e o sentido da liberdade, tendo em vista o estabelecimento de novas relações entre o homem e a natureza. Afirmou que a pesquisa a ajudou a ter um melhor conhecimento do lado humano do processo de formação dos alunos para os quais leciona como professora de Biologia, 
mas não fez referência à realização de nenhum trabalho empírico com esses alunos.

Correia (2002) fez uma pesquisa documental baseada principalmente nos PCN, tendo como perspectiva compreender por que a ética foi apontada como tema transversal, os propósitos de se trabalhar com ela e como o trabalho pode ser desenvolvido em sala de aula. O autor não mencionou o quadro teórico-metodológico que balizou a investigação, mas concluiu que a ética, vista como saber escolar em uma perspectiva antropológica, pode contribuir para a construção da autonomia e da emancipação do homem.

Silva (2001) também analisou o volume relativo à ética dos PCN, focalizando a questão da pragmática da linguagem a partir do referencial teórico-metodológico de John Searle, qual seja, a teoria dos atos de fala. Não se reportou, porém, às conclusões a que o trabalho chegou.

Barros (2001) procurou investigar como a ética era tratada no ensino fundamental I e, para tanto, realizou um estudo de caso etnográfico em uma escola confessional no município de São Paulo. A empiria foi conduzida a partir de entrevistas com professoras e da análise de trabalhos feitos pelos alunos. A principal conclusão foi a de que a ética é um tema a ser inserido na formação do professor, pois perpassa todo o seu cotidiano.

Por fim, a pesquisa desenvolvida por Gama (2009) tomou por objeto uma escola municipal situada em Natal (RN) com o propósito de investigar indicadores éticos nas atividades desenvolvidas pelo Centro Ginástico deste estabelecimento de ensino. Tendo como quadro teóricometodológico a análise de conteúdo proposta por Bardin, incorporou, ainda, contribuições de Maturana, Morin e Paulo Freire. Apontou, como principal conclusão, que a ética em aulas de educação física é de suma importância para pensar a educação a partir de uma perspectiva voltada para a formação humana.

Entre os trabalhos mencionados, nenhum tomou como objeto específico a visão de ética dos alunos, o que sugere ser esse um foco pouquíssimo explorado pelos estudos voltados para a problemática da ética na escola de ensino fundamental.

\section{b) O que dizem as propostas parlamentares?}

Com a Lei de Diretrizes e Bases da Educação Nacional n 9.394/96 (LDB) e a divulgação dos Parâmetros Curriculares Nacionais (PCN), a discussão acerca da ética e da cidadania tornou-se mais corrente, uma vez que tais documentos apontam esses termos como elementos-chave para a educação no País. Observa-se, nesse sentido, que as discussões envolvendo o conceito de ética, moral e civismo estiveram e ainda estão presentes no campo educacional, seja mediante disciplinas como Educação Moral e Cívica, Organização Social e Política Brasileira, Estudo dos Problemas Brasileiros, pela via do Ensino Religioso, ou, mais recentemente, por meio dos temas transversais.

No período compreendido entre 1997 e 2010, alguns congressistas apresentaram proposições tanto na Câmara Federal quanto no Senado, 
visando reintroduzir nas escolas o estudo da ética como uma disciplina curricular obrigatória, apesar de o tema já ser contemplado nos PCN de forma transversal.

Em vista disso, realizamos um levantamento pela via eletrônica, buscando identificar os projetos de lei apresentados, seus autores e suas justificativas. Nessa busca, localizamos cinco projetos relativos à ética no ensino básico, relacionados a seguir.

O deputado Victor Pires Franco Neto, do PFL/PA (atual DEM), apresentou, em 9 de junho de 1999, o Projeto de Lei no 1.131, que torna obrigatória a inclusão da disciplina Ética e Cidadania nos currículos escolares dos estabelecimentos de ensino fundamental e médio das redes pública e privada em todo o País. Conforme o projeto, a educação escolar constitui-se instância de formação e cidadania de crianças, adolescentes e jovens. Logo, o currículo escolar da educação básica deve contemplar noções básicas de direitos e deveres, valores e atitudes, e essa tarefa deve ser cumprida pelo oferecimento da disciplina Ética e Cidadania, cuja finalidade será "a construção de uma nova escola e de uma nova geração de brasileiros com uma mentalidade cidadã". O projeto foi arquivado pela mesa diretora da Câmara em 16/3/2000.

O Projeto de Lei no 3.379, de autoria do deputado Chico Sardelli do PFL (atual DEM) de São Paulo, apresentado em 29 de junho de 2000, prevê que "constituirá componente curricular obrigatório Ética, Moral e Civismo, com o objetivo de promover sistematicamente o desenvolvimento do educando". A partir da inclusão dessa disciplina, entende que

[...] se estaria dando voz e vez aos estudantes, famílias e professores que, impressionados com a violência, a falta de respeito e a desordem que marcam o dia-a-dia de muitas escolas, denunciam a omissão das instituições de ensino em matéria de temas axiológicos, morais e éticos e reclamam políticas disciplinares, sistemas de referência, balizamentos.

Sardelli não acredita que as oportunidades do aprendizado de valores, da formação do caráter, da prática de respeito à pessoa do outro, do exercício da disciplina, da justiça e do comportamento socialmente responsável podem ficar por conta dos temas transversais e que essas oportunidades devem ser oferecidas de forma sistemática, intencional e obrigatória. A obrigatoriedade da inclusão de ética, moral e civismo nos currículos da educação básica "responde a um anseio da sociedade e torna possível que haja efetiva cobrança às instituições de ensino por parte de conselhos escolares e alunos". O autor, dessa maneira, acredita que a voz da sociedade seria ouvida pela inclusão da disciplina Ética, Moral e Civismo que ele propõe. O projeto havia sido arquivado pela mesa diretora da Câmara, mas foi desarquivado em 15/2/2011 em função de um recurso e aguarda deliberação.

De autoria do deputado Fernando Zuppo do PDT de São Paulo, foi apresentado, em 29 de novembro de 2000, o Projeto de Lei no 3.857, que propõe que os currículos escolares, do ensino fundamental ao superior, incluam o ensino da ética e da cidadania como parte de seus conteúdos. 
Segundo Zuppo, "temos, no mundo contemporâneo, consenso que os valores éticos e da cidadania constituem-se em elemento fundante de uma sociedade democrática que se queira construir com base na justiça e na igualdade social". Logo, segundo o autor, o ensino daqueles valores, em todos os níveis e para todos os alunos, não pode ser apenas parte de um conjunto de conteúdos genericamente contemplados nos PCN. O projeto foi apensado ao PL apresentado pelo deputado Chico Sardelli, encontrando-se hoje na mesma situação (aguardando deliberação de recurso).

Essas três proposições apresentam em comum o fato de afirmarem que o tema ética, pela sua relevância, não pode ser apresentado nas escolas de forma transversal, mas deve ser sistematizado em uma disciplina obrigatória, o que permitirá construir e resgatar, segundo seus autores, valores perdidos pela sociedade e pela escola.

O Projeto de Lei no 7.425, de autoria do senador Pedro Simon do PMDB do Rio Grande do Sul, foi apresentado em agosto de 2006 e visa promover a inclusão nos ensinos fundamental e médio, assim como nos cursos de formação de professores da educação básica, de um componente curricular voltado para a difusão de valores ligados à ética e à cidadania. Segundo Simon,

[...] diante do tempo cada vez mais exíguo que muitos pais dispõem para conviver com seus filhos, educando-os adequadamente, e também diante do papel por vezes deletério que os meios de comunicação de massa, particularmente a televisão, assumem na formação das personalidades das crianças e adolescentes, a criação de um componente curricular para a abordagem de questões éticas e cívicas se reveste de inequívoca importância.

O senador afirma que o rumo da disciplina é a defesa do pluralismo, a rejeição de qualquer forma de preconceito ou discriminação e o estímulo à ação comunitária e que "a presente proposta tem por finalidade romper com a visão cada vez mais predominante de que a escola de nível básico deve tão somente transmitir informações e saberes que tenham utilidade para a vida profissional ou para a continuidade dos estudos em nível superior". Para ele, "é preciso rejeitar essa concepção puramente instrumental da escola, tornando mais consequente o fato de que ela é também responsável pela formação ética e cívica dos estudantes". O projeto foi arquivado pela mesa diretora da Câmara em 6/9/2007.

O Projeto de Lei no 3.393, de autoria do deputado Humberto Souto (PPS-MG), foi apresentado em 3 de setembro de 2008 e propõe a inclusão na grade do ensino fundamental de um componente curricular dedicado ao cultivo dos valores éticos e de cidadania. Tomando por base atividades desenvolvidas em escolas, como seminários sobre ética e cidadania, o deputado argumenta "ser absolutamente necessário incluir a disciplina nos currículos de ensino fundamental, sobretudo se levarmos em conta o índice de criminalidade e o baixo desempenho de alunos na rede pública". O projeto foi apensado ao PL $n^{\circ}$ 2.082/2003, que aguarda parecer na Comissão de Finanças e Tributação da Câmara dos Deputados, para a 
qual foi encaminhado, após arquivamento e posterior desarquivamento, em 11 de abril de 2011.

Nenhum acontecimento pode ser pensado isoladamente, pois é histórica e culturalmente situado. Não obstante os processos de arquivamento e desarquivamento, comuns na rotina de trabalho da Câmara Federal, esses projetos de lei refletem aspirações existentes na sociedade brasileira. Perguntamos, então: que fatos podem ter impulsionado sua elaboração? É provável que a entrada do século 21, com o aumento da velocidade de acesso à informação e sua popularização em redes de conexão, bem como inúmeros escândalos de corrupção e casos de violência urbana, entre outras explicações, justifiquem a produção de projetos de lei ancorados na ética como instância de redenção das mazelas sociais e da "crise moral", na qual, segundo esses parlamentares, se encontra imersa a sociedade atual.

\section{Quadro teórico metodológico}

Entre os anos 1950 e 1958, Chaïm Perelman e Lucie Olbrechts-Tyteca, pesquisadores da Universidade Livre de Bruxelas, desenvolveram uma teoria da argumentação, a qual chamaram também de nova retórica. O que motivou os autores a fazer tal estudo foi a busca de uma lógica que pudesse dar conta dos enunciados conhecidos como juízos de valor (Pedro é honesto, por exemplo), pois estes haviam sido considerados "irracionais" pelos positivistas lógicos. A "irracionalidade" residiria no fato de não poderem ser determinados como verdadeiros ou falsos, na medida em que não existiam critérios lógicos e/ou empíricos para proceder a tal determinação.

Conscientes de que as ciências humanas não são neutras e que, portanto, os investigadores que atuam nessas áreas não prescindem dos juízos de valor, Perelman e Olbrechts-Tyteca se lançaram à pesquisa, mas ao final concluíram que aquilo que procuravam já havia sido formulado, não no campo da lógica, mas no da antiga retórica dos gregos e romanos. No estudo realizado sobre obras de Aristóteles (1983, 1991), como os Tópicos e a Retórica, os dois autores perceberam que os juízos de valor eram bem apreciados a partir de uma racionalidade de tipo não coercivo, isto é, que não impõe conclusões com base no que é verdadeiro ou falso, mas no que é considerado verossímil.

Assim, um enunciado do tipo ele é um bom orador não tem como ser considerado verdadeiro ou falso, mas pode ser verossímil ou não, consoante a apreciação do auditório que o escuta. A partir daí, Perelman e Olbrechts-Tyteca (2005, p. 7) definiram as categorias básicas de sua teoria da argumentação:

O que conservaremos da retórica tradicional é a ideia mesma de auditório, que é imediatamente evocada assim que se pensa no discurso. Todo discurso se dirige a um auditório, sendo muito freqüente esquecer que se dá o mesmo com todo escrito. [...] 
Assim, por razões de comodidade técnica e para jamais perder de vista esse papel essencial do auditório, quando utilizarmos os termos "discurso", "orador" e "auditório", entenderemos com isso a argumentação, aquele que a apresenta e aqueles a quem ela se dirige, sem nos determos no fato de que se trata de uma apresentação pela palavra ou pela escrita, sem distinguir discurso em forma e expressão fragmentária do pensamento.

Para interpretar o discurso, os autores elaboraram uma classificação que reúne as técnicas argumentativas em dois grandes grupos: técnicas de ligação e técnicas de dissociação. As primeiras buscam estabelecer vínculos entre elementos separados ou cuja relação não é imediatamente percebida pelo auditório. Já as técnicas de dissociação fazem o inverso, buscando mostrar que os elos considerados ou o caráter unívoco de uma noção não procedem.

Os argumentos classificados no primeiro grupo subdividem-se em quase-lógicos, baseados na estrutura do real e que fundamentam a estrutura do real. Os quase-lógicos recebem essa denominação pela semelhança que têm com as relações lógicas (identidade, inclusão, transitividade, simetria, etc.), derivando exatamente daí sua força persuasiva. Os baseados na estrutura do real sugerem relações de sucessão (vínculo entre causa e consequência ou entre meios e fins) ou de continuidade (relação entre a pessoa e seus atos, por exemplo), enquanto os que fundamentam a estrutura do real sugerem vínculos novos a partir de vinculações já conhecidas, como no caso das analogias. Por sua vez, as técnicas de dissociação podem se dar por meio da ruptura de ligação, que separa elementos vinculados, ou por meio da dissociação de noções, que desdobra um termo, sugerindo para ele um novo significado, mais condizente na visão do orador.

A classificação é extensa e pormenorizada, mas para os fins do presente trabalho nos deteremos nos argumentos quase-lógicos, mais especificamente nas definições, que apresentam-se inseridas nesse grupo. Isso porque a questão central da pesquisa ("o que você entende por ética?") pede ao respondente que expresse seu pensamento por meio de uma definição. Segundo Perelman e Olbrechts-Tyteca (2005, p. 238):

O procedimento mais característico de identificação completa consiste no uso das definições. Estas, quando não fazem parte de um sistema formal e pretendem, não obstante, identificar o definiens com o definiendum, serão consideradas, por nós, argumentação quase-lógica. Não podemos admitir que essas definições possam ser fundamentadas na evidência de relações nocionais, ${ }^{2}$ pois isso suporia a clareza perfeita de todos os termos cotejados.

A partir daí, Perelman e Olbrechts-Tyteca (2005, p. 239) propõem quatro tipos de definições:

a) normativas: indicam a forma que se quer que um termo ou noção seja empregado, a qual deriva de uma regra explícita que se crê válida para o próprio indivíduo ou para todos; \begin{tabular}{l}
\hline Os autores querem dizer que \\
definições do tipo "triângulo \\
é toda figura fechada de três \\
lados" são lógicas, porque o \\
definiendum pode ser permutado \\
com o definiens sem gerar \\
qualquer dúvida ou contestação: \\
"toda figura fechada de três lados \\
é denominada triângulo".
\end{tabular} 
b) descritivas: indicam o sentido conferido a um termo ou noção em um dado meio ou em dado momento. Não expressam diretamente uma regra, embora possam sugeri-la;

c) de condensação: destacam os elementos essenciais de uma definição descritiva, sendo bastante sucintas;

d) complexas: combinam de modo variável aspectos das outras três definições.

Buscaremos, então, no tópico seguinte, classificar, na medida do possível, as respostas tomadas para análise com base nesses tipos, separando-as de outra categoria, SD (sem definição), que reúne respostas como "não sei", as deixadas em branco e aquelas cuja redação carece de sentido.

Discípulo de Perelman na Universidade Livre de Bruxelas, Michel Meyer tem aprofundado os estudos no campo argumentativo, salientando que qualquer resposta a uma questão pode ser considerada de tipo problematológico ou apocrítico (Meyer, 1998). As respostas problematológicas são aquelas que remetem a novas perguntas pelo fato de deixarem elementos em aberto. Já as apocríticas encerram a discussão por responderem de um modo que não permite o questionamento. Se, por exemplo, perguntarmos: Quem é João? e o respondente disser que É um amigo muito prestativo, poderemos colocar-lhe outra questão: $O$ que você considera ser prestativo? Se, todavia, obtivermos como resposta que João é um amigo meu, não há mais o que perguntar sobre esse enunciado, pois a resposta é apocrítica e não suscita dúvidas.

Para Meyer, a capacidade de problematização se vincula à diferença que se coloca entre a pergunta e a resposta (desde que não seja apocrítica), que ele denomina diferença problematológica:

No processo de questionamento, é preciso conseguir distinguir entre aquilo que está em questão e aquilo que está fora de questão. Chamase a isso diferença problematológica, sem a qual seria impossível questionar e responder, uma vez que ambas seriam o mesmo. Ora, se tudo fosse problemático não saberíamos sequer aquilo que perguntamos. Pela interrogatividade, notemo-lo bem, vamos para além do dilema insolúvel do realismo e do idealismo, que sofrem ambos da mesma negação do questionamento que é fulcral na determinação dos objectos. Com efeito, estes não se dão completamente feitos, é preciso questionar sempre antes de obter uma resposta. (Meyer, 2005, p. 55).

A análise de um enunciado fornecido como resposta é tão mais rica quanto maior for a diferença problematológica com relação à pergunta que lhe deu origem. Em vista disso, buscaremos problematizar algumas das definições fornecidas pelos alunos, tomando as respostas que consideramos de natureza mais problematológica. Quando propomos questões de cunho reflexivo, não há critérios objetivos para medir quão problematológica é uma resposta, contudo as mais originais tendem a estimular o questionamento, enquanto as mais previsíveis e sucintas, não.

Além disso, o trabalho interpretativo que desenvolvemos a partir da problematização das definições de ética (e para o qual contamos com 
subsídios fornecidos pelas respostas a outras questões propostas - 4, 4.1, 4.2, 4.3 e 4.4) ${ }^{3}$ tem por objetivo, como salienta Meyer (1998, p. 22), "fazer passar o verossímil, a opinião e o provável com boas razões e argumentos, sugerindo inferências ou tirando-as por outrem".

Conforme comentamos anteriormente, nosso propósito foi fazer um estudo exploratório, que, nas palavras de Caleffe e Moreira (2006, p. 69), é o que "tem como principal finalidade desenvolver, esclarecer e modificar conceitos e ideias, com vista à formulação de problemas mais precisos ou hipóteses posteriores".

Entendemos também que a pesquisa realizada corresponde a um estudo de caso, embora não exaustivo, pois empregou como instrumento de coleta de dados um questionário. Outros procedimentos, como entrevista e grupo focal, que permitiriam uma triangulação de técnicas, não foram autorizados pela direção da escola. Embora reconhecendo as limitações do instrumento utilizado, que pode coletar dados superficiais e/ou de cunho descritivo e não explicativo (Caleffe, Moreira, 2006, p. 97), avaliamos que teríamos as seguintes vantagens: "uso eficiente do tempo", "anonimato para o respondente", "possibilidade de uma alta taxa de retorno" e "perguntas padronizadas" (p. 96). De fato, os estudantes sentiram-se bem mais à vontade quando souberam que não precisariam ser identificados, e a taxa de retorno foi de 100\% nas duas turmas (oitavo e nono anos) pesquisadas.

\section{Análise argumentativa das respostas dadas pelos alunos}

\section{a) Perfil discente}

O questionário foi respondido por um total de 64 alunos, 29 de oitavo ano e 35 de nono ano. Nas duas turmas, em um universo de 64 respostas, há equilíbrio entre os sexos e, no cômputo geral, ligeira predominância do sexo masculino (51,6\%) em relação ao feminino (48,4\%). A faixa etária mais comum no oitavo ano (entre 13 e 14 anos) não é significativamente expressiva, pois, das 27 respostas fornecidas, 15 (55,5\%) se acham compreendidas nela e 11 (40,7\%) estão além dela (15 ou 16 anos), havendo apenas uma indicação de idade inferior a 13 anos. No nono ano, das 34 respostas obtidas, $24(70,6 \%)$ estão na faixa etária mais comum (entre 15 e 16 anos), havendo oito indicações (23,5\%) de faixa etária menor (14 anos) e duas (5,9\%) de faixa etária maior.

Os percentuais do nono ano são compatíveis com as expectativas de percurso escolar previsto para estudantes que não tenham enfrentado problemas de retenção no ensino fundamental, mas no oitavo ano tais problemas provavelmente ocorreram. Com respeito ao perfil socioeconômico, 58 respondentes se declararam "nem ricos, nem pobres" (90,6\%), 5 disseram ser "pobres" (7,8\%) e 1 se declarou "rico". Esses dados revelam a predominância de um alunado de classe média, contudo é preciso levar em consideração que os respondentes podem ter tomado
${ }_{3}^{3}$ As respostas dadas às questões 2 (que teve por foco dilemas éticos/morais) e 3 (que visou constatar como e por que os oradores hierarquizavam os valores "bem" e "útil") deverão ser trabalhadas em um próximo artigo. 
como parâmetro de "riqueza" e "pobreza" o que conhecem acerca da renda familiar de seus colegas, comparando-se, então, com eles, o que nos sugere que essa classificação pode se referir a subcategorias dentro de uma mesma classe socioeconômica.

Em relação à estrutura familiar, 64 respostas foram obtidas: 49 alunos $(76,6 \%)$ disseram morar com os pais, 14 (21,9\%) com somente um deles e um em companhia de parentes, não havendo quem declarasse morar apenas com outras pessoas. Quanto às atividades de lazer desenvolvidas por esses jovens, dentre as 64 respostas fornecidas constatamos haver grande diversificação. A alternativa "sair com amigos" foi apontada como a favorita por $10(15,6 \%)$ alunos. A prática de esportes obteve 21 indicações $(32,8 \%)$ e o uso do computador, 24 (37,5\%). Apenas 7 estudantes (10,9\%) indicaram ter preferência pelas atividades artístico-culturais.

\section{b) Análise do que os oradores entendem por ética}

Das 64 respostas dadas à questão 1, 8 (12,5\%) foram enquadradas no tipo SD. Dentre as restantes, selecionamos $8(12,5 \%)$ para análise, tendo em vista o que discutimos no tópico anterior acerca do conteúdo problematológico de uma resposta. A redação original dos oradores foi respeitada, sem haver nenhum tipo de correção.

É significativo destacar que 42 oradores $(65,6 \%)$ estabeleceram vínculos com a educação em suas definições de ética. A educação, aliás, foi a palavra ligada à ética mais citada na questão 4, obtendo um total de 50 menções (83,3\%). O termo foi majoritariamente compreendido no sentido de ser bem comportado e polido, ou seja, cultivar bons hábitos; apenas 5 oradores $(7,8 \%)$ o relacionaram de algum modo à palavra moral, seu oposto (imoral) ou seus derivados (moralidade); 34 (53,1\%) estudantes indicaram-no como o mais ouvido na escola (questão 4.1), o que leva a crer que a importância que lhe conferem é devida não só ao trabalho educativo escolar, mas ao que ouvem fora da escola, provavelmente no ambiente familiar.

A vinculação da ética à educação, vista preferencialmente como ação reguladora do comportamento, indica que a visão dos oradores é fortemente marcada pela heteronomia, o que aponta para uma formação ética/moral situada na contramão do que defendem os PCN e o Relatório Delors, os quais ressaltam a importância da formação de sujeitos autônomos.

Iniciando a análise argumentativa das definições selecionadas, constatamos que a oradora de número 2 empregou uma definição normativa para a ética (Anexo 2), pondo em destaque a regra que prescreve ter respeito, bom comportamento e ser educado com os mais velhos. Tal regra corresponderia a uma orientação ética/moral que lhe foi prescrita pela família (heteronomia)? Na resposta dada à questão 4.1 (que pedia para o respondente mencionar três palavras ligadas à ética), a discente afirmou que na escola não ouve "nenhuma, porque eles são 
mal educados". As palavras mencionadas na questão 4 foram respeito, dignidade e educação. Esse depoimento corrobora a visão externada pelas propostas parlamentares que entendem ser preciso intervir na grade curricular para que a escola resgate os valores éticos perdidos.

Na medida em que a boa educação, compreendida como comportar-se de um modo que é prescrito por outrem, se coloca para essa aluna como algo vindo de fora, que papel a educação escolar cumpre para ela? Provavelmente apenas o de transmitir conteúdos (como critica o projeto de lei do senador Pedro Simon), e não o de contribuir para que haja mudanças em sua vida, conforme podemos inferir da resposta dada à questão 4.4: "[...] eu, meus amigos e minha família nos respeitamos, somos educados e temos dignidade".

O orador de número 5 também apresentou uma definição normativa (Anexo 2) baseada, a exemplo de muitos dos seus colegas, em uma regra referente ao bom comportamento. A noção de "saber se comportar" parece óbvia para os oradores que se reportaram a ela, de sorte que à pergunta $O$ que é saber se comportar? provavelmente responderiam de modo apocrítico. Além da ênfase na questão comportamental, esse aluno mencionou, na questão 4.2, a atitude de ajudar a outras pessoas: "ajudar o mais próximo". Fica, naturalmente, a dúvida acerca do sentido da resposta, pois não está claro se o orador quis dizer "ajudar mais o próximo" ou se de fato fez referência àqueles que constituem seu círculo mais íntimo de relações.

Na visão do orador de número 7 (Anexo 2), a convivência é ressaltada por meio de uma definição condensada. Considerando o conjunto das respostas fornecidas, esta foi selecionada por ser uma das poucas que não se reporta explicitamente ao bom comportamento. Em que sentido, porém, a convivência com as pessoas estaria sendo compreendida? Reportando-nos às palavras relacionadas à ética, a educação, o respeito e a bondade foram citados, sendo que a primeira foi entendida como a "educação da humanidade". Isso sugere que o orador tem preocupações que não se limitam ao círculo imediato das relações familiares e escolares, assumindo uma perspectiva de caráter mais universal. Tal interpretação é fortalecida pela resposta dada à questão 4.4: "sim e não. Porque na minha vida, que eu vivo, existem pessoas que se acham o dono do mundo". O pleonasmo parece querer enfatizar, justamente, que nos círculos mais próximos deste estudante as pessoas não conseguem conviver bem entre si, provavelmente porque pensam apenas em si mesmas e não no outro.

O orador de número 8 apresentou uma definição descritiva (Anexo 2), cujo foco foram os professores, ou, mais precisamente, a qualidade do trabalho desenvolvido por eles na escola. Podemos perguntar, então: para este aluno, seriam éticos os professores que educam bem e não éticos os que educam mal? As demais respostas parecem apontar para essa conclusão, já que como palavras ligadas à ética ele mencionou a educação, o respeito e a justiça. Em relação à primeira, afirmou que "Educação é um meio mais importante de aprender", sugerindo que os docentes que "não educam" prejudicam os alunos. Tal atitude tem repercussões mais 
amplas, conforme podemos constatar pela resposta dada à ultima questão: "Sim, porque sem educação não aprendemos, sem justiça os criminosos vivem livremente e sem respeito nunca seremos educados". É interessante destacar a série de vínculos causais estabelecidos, os quais permitem reforçar a interpretação de que os professores que "não educam" não são éticos, na medida em que não têm respeito pelos alunos.

Uma definição complexa foi trazida pelo orador de número 24 (Anexo 2), que situou a ética com respeito à educação familiar e também à conduta assumida nas relações cotidianas. A esta descrição, vinculou a regra de cultivar um agir pautado por princípios. Mas o que tal termo significaria para este estudante? Uma das palavras citadas por ele na questão 4 caráter - nos fornece alguns elementos, pois foi compreendida como "manter honestidade em qualquer momento". Tal compreensão remete a um imperativo de tipo categórico, o qual é ilustrado pela seguinte situação (resposta à questão 4.3) mencionada pelo orador: "receber o troco a mais e dizer ao vendedor, não saindo com mais e se sentir bem". A partir daí, pode-se compreender melhor o que esse aluno quis dizer quando se referiu a princípios: ele os considera em termos absolutos, isto é, como diretrizes a serem respeitadas independentemente da situação existencial em que o sujeito se acha envolvido.

A oradora de número 36 também empregou uma definição complexa (Anexo 2), que destaca a educação e a combina com uma regra de conduta aplicável em diferentes "momentos". Tal regra diria respeito ao bom comportamento mencionado por outros alunos? As demais respostas fornecidas pela estudante não sugerem essa interpretação. Como palavras ligadas à ética, citou educação, respeito e paz. Esta última foi compreendida como "fazer só coisas boas para um mundo melhor" e complementada pela seguinte observação, dada em resposta à questão 4.3: "paz: uma coisa que está faltando para o mundo todo". Com relação às contribuições que as referidas palavras trazem para sua vida, a aluna escreveu: "sim. Educação e respeito vão contribuir na minha vida para o crescimento do meu filho". Em seu perfil, ela afirmou ter 16 anos e morar com o marido e o filho, o que a situa em um plano relacional diferente com respeito aos seus colegas: a questão de "saber se comportar" de acordo com padrões ditados pela família não se faz mais presente, ou pelos menos não parece ser tão presente em seu cotidiano. Em contrapartida, como mãe, assume responsabilidades e nutre expectativas com relação a viver em um mundo melhor, condição que também almeja para o filho.

A definição apresentada pelo orador de número 40 (Anexo 2) pode ser situada como normativa, pois os princípios invocados por ele dizem respeito a uma regra que norteia sua conduta: seguir a educação dada pelos pais. Quanto a essa regra, cabe perguntar se é aplicável ao conjunto de situações existenciais do estudante. As demais respostas fornecidas indicam que parece não haver exceções. Assim, as três palavras ligadas à ética foram moralidade, educação e princípios. A primeira foi compreendida no sentido de uma "pessoa que respeita as outras e a si mesma" e, a segunda, como "o básico de uma pessoa moral". Já a terceira 
repete a definição apresentada para ética: "educação recebida durante a vida (vinda dos pais)." Por sua vez, as situações relacionadas a cada uma delas buscaram enfatizar que a regra se aplica em diferentes contextos e lugares:

\begin{abstract}
Moralidade: no ônibus, pessoa que não se levanta da cadeira para os mais idosos sentarem.

Educação: na escola, aqueles que não respeitam as pessoas e, em casa, que não respeitam nem os pais ou parentes.

Princípios: na rua, pessoas se cumprimentam com palavrões desrespeitando pai e mãe dos outros.
\end{abstract}

É interessante notar que a moralidade foi definida a partir do que seria o seu inverso (deixar de agir moralmente), assim como os princípios (não possuir) e a educação (não ter respeito por ninguém), mas, de todo modo, a conduta correta, oriunda da educação, se coloca como fruto de uma orientação heterônoma, que o orador segue sem, aparentemente, questionar.

A oradora de número 44 fornece uma definição normativa para a ética (Anexo 2), a qual pode ser problematizada a partir do questionamento do que ela entende acerca dos termos que mencionou. Estes se vinculam às palavras citadas na questão 4, inteligência, moralidade e educação, que foram compreendidas do seguinte modo: inteligência - "saber e entender"; moralidade - "saber como agir e se comportar"; e educação - "saber falar e também ter entendimento". Podemos perceber que há circularidade de ideias na explicitação das noções, que se mantêm na referência às situações existenciais (questão 4.3), como, por exemplo, quando a estudante se reporta à moralidade ("saber o que falar, como se expressar e se comportar corretamente") e também às mudanças (questão 4.4) processadas em sua vida ("sim, pois com elas sou mais educada, inteligente e moral"). A circularidade, por sua vez, sugere que a oradora basicamente repete o que lhe é incutido pela educação recebida, sem assumir posturas mais críticas.

Na definição descritiva que dá para a ética, a oradora de número 47 enfatiza uma série de aspectos que podem ser salientados como qualidades não necessariamente vinculadas ao bom comportamento, todavia é importante questionar se essa realmente é uma suposição factível. As outras respostas não sugerem isso, pois, embora as palavras respeito e dignidade - mencionadas como possuindo ligação com a ética - tenham sido compreendidas, respectivamente, como "dar respeito ao outro" e "ser digno de si mesmo", a educação sublinha as relações heterônomas que regulam o comportamento da estudante: "educação - uma pessoa educada, que tenha modos e seja gentil". A situação associada a ela também: "é quieta, fala quando deve, pede licença e sempre pede obrigada". Corroborando o que foi dito, a resposta dada à questão 4.4 sintetiza o ponto de vista dessa oradora: "sim, todos me acham uma menina muito educada, respeito meus pais e os mais velhos e sou muito digna". 


\section{Conclusões}

A partir das respostas dadas à primeira questão foi possível concluir que a pergunta exigiu esforços dos estudantes para definir o que entendem por ética. Isso nos faz pensar que não há, nessa escola, um trabalho mais sistematizado por parte dos agentes escolares (direção, coordenação pedagógica, orientação educacional e corpo docente) no sentido de levar os alunos a uma reflexão mais detida sobre questões éticas/morais. O cruzamento dos dados quantitativos e qualitativos aponta indícios de que a heteronomia se impõe sobre a autonomia ética/moral e que as orientações heterônomas partem principalmente das famílias.

A predominância da heteronomia nas relações educativas que balizam a formação dos alunos dessa escola vai ao encontro das propostas parlamentares que desejam a inclusão da ética como disciplina nos currículos escolares, na medida em que estas consideram ser preciso ensinar os valores "perdidos". Isso é preocupante, pois se coloca em direção oposta ao que preconizam os PCN e o Relatório Delors, cujas abordagens enfatizam a importância de a ética ser introduzida no espaço escolar a partir de uma perspectiva que incentive o desenvolvimento da autonomia do educando.

O trabalho hermenêutico desenvolvido com base na problematização dessas respostas permitiu chegar à conclusão de que o perfil ético/ moral desses alunos é eminentemente de cunho não crítico em relação a hábitos e formas de conduta apresentados como padrão do chamado bom comportamento.

A pouca autonomia desses estudantes pode também ser associada a uma menor liberalização dos costumes e a um controle mais rígido dos seus hábitos e atitudes, provavelmente comum no ambiente social em que vivem. Contribui para essa interpretação o fato de que, nessa escola, a opção de lazer "sair com amigos" obteve um percentual de indicação $(15,6 \%)$ baixo se comparado às opções "prática de esportes" e "uso do computador", que obtiveram, respectivamente, 32,8\% e 37,5\%.

Embora não tenha sido objetivo deste artigo analisar os perfis dos oradores das duas escolas particulares em que o questionário também foi aplicado, vale salientar que a vinculação entre ética e educação não foi tão significativa, ${ }^{4}$ como também a compreensão da educação como algo ligado à polidez e ao bom comportamento não foi predominante, sugerindo a existência de maior autonomia nas relações desses estudantes com os meios familiar e escolar.

Finalmente, como ponto de partida para investigações posteriores, que trabalhem com amostragens socialmente mais diversificadas e quantitativamente mais expressivas, fica a questão de se a maioria dos alunos dos anos terminais do ensino fundamental no município do Rio

4 Em ambas as escolas, a educação foi somente a quarta palavra mais citada na questão 4, obtendo $18,8 \%$ de indicações em uma delas e $14,3 \%$ na outra. de Janeiro considera ou não a ética como conjunto de regras a priori, as quais é preciso seguir sem maiores questionamentos. Tal visão se opõe à que foi aqui defendida: tomar a ética/moral como construto de caráter intersubjetivo que, para ostentar o estatuto de um acordo majoritário, 
toma como fundamental o confronto entre diferentes pontos de vista por meio de práticas argumentativas.

\section{Referências bibliográficas}

ARISTÓTELES. Tópicos. São Paulo: Abril Cultural, 1983. p. 3-152.

(Coleção: Os pensadores).

ARISTÓTELES. Rhétorique. Paris: Librairie Génerale Française, 1991.

BARROS, Anaqueila Garcia de. Alfabetizando para o mundo: estudo de caso sobre ética no Ensino Fundamental I. 102 p. Dissertação (Mestrado) - Universidade Presbiteriana Mackenzie, São Paulo, 2001. 2 v.

BRASIL. Ministério da Educação e Cultura (MEC). Secretaria de Educação Fundamental (SEF). Parâmetros Curriculares Nacionais: terceiro e quarto ciclos - apresentação dos temas transversais. Brasília: MEC/SEF, 1998a.

BRASIL. Ministério da Educação e Cultura (MEC). Secretaria de Educação Fundamental (SEF). Diretrizes Curriculares Nacionais do ensino fundamental: relatório. Brasília: MEC/SEF, 1998b. Disponível em: <portal.mec.gov.br/index.php?Itemid =\&gid=852\&option $=$ com $>$. Acesso em: 21 maio 2011.

BRASIL. Projeto de Lei no 1.131 de 9 de junho de 1999. Dispõe sobre a inclusão obrigatória da disciplina Ética e Cidadania nos currículos escolares dos estabelecimentos de ensino fundamental e médio, das redes pública e privada em todo País. http://www2.camara.gov.br. Acesso em: 28 jun. 2011.

BRASIL. Projeto de Lei no 3.379 de 29 de junho de 2000. Dispõe sobre a obrigatoriedade de inclusão das disciplinas, ética, moral e civismo, no currículo do ensino fundamental, indo além do tratamento dado a esses temas nas diretrizes e nos parâmetros curriculares nacionais, por conta dos chamados temas transversais. http://www2.camara.gov.br. Acesso em: 28 jun. 2011.

BRASIL. Projeto de Lei n. 3.857 de 29 de novembro de 2000. Dispõe sobre a inclusão do ensino de Ética e Cidadania nos currículos escolares. http://www2.camara.gov.br. Acesso em: 28 jun. 2011.

BRASIL. Projeto de Lei no 7.425 de 16 de agosto de 2006. Acrescenta e altera dispositivos na Lei no 9.394, de 20 de dezembro de 1996, para incluir no ensino fundamental e médio, e nos cursos de formação de 
professores da educação básica, componente curricular dedicado ao desenvolvimento de valores éticos e de cidadania. http://www2.camara. gov.br. Acesso em: 28 jun. 2011.

BRASIL. Projeto de Lei no 3.393 de 3 de setembro de 2008. Altera dispositivos na Lei $n^{\circ}$ 9.394, de 20 de dezembro de 1996, para incluir no ensino fundamental um componente curricular voltado para o cultivo de valores éticos e de cidadania. http://www2.camara.gov.br. Acesso em: 28 jun. 2011.

CALEFFE, Luiz Gonzaga; MOREIRA, Herivelto. Metodologia da pesquisa para o professor pesquisador. Rio de Janeiro: DP\&A, 2006.

CARVALHO, Diógenes Gonçalves de. Ética no cotidiano escolar. 144 p. Dissertação (Mestrado) - Universidade do Oeste Paulista, 2004.

CORREIA, Wilson Francisco. Ethos, educação e currículo: a ética como saber escolar. 168p. Dissertação (Mestrado em Educação) Universidade Federal de Uberlândia, 2002.

GAMA, Leonardo Rocha da. Ginástica e ética na escola: apontamentos para compreender a convivência humana. 2009. 217 p. Dissertação (Mestrado em Educação) - Universidade Federal do Rio Grande do Norte, Natal, 2009.

KANT, Immanuel: Crítica da razão prática. Lisboa: Edições Setenta, 1997.

MEYER, Michel. Questões de linguagem, retórica, razão e sedução. Lisboa: Edições Setenta, 1998.

MEYER, M. Qu'est-ce que l'argumentation? Paris: Vrin, 2005.

PERELMAN, Chaïm; OLBRECHTS-TYTECA, Lucie. Tratado da argumentação: a nova retórica. São Paulo: Martins Fontes, 2005.

RODRIGUES, Tânia Thibes. Desafios éticos no contexto escolar. 2000. 77 p. Dissertação (Mestrado em Educação) - Universidade Federal do Paraná, Curitiba, 2000.

SAMARANCH, Francisco. Cuatro ensayos sobre Aristóteles. Buenos Aires: Fondo de Cultura Económica, 1991.

SILVA, Humberto Pereira da. Ensino de ética nos Parâmetros Curriculares Nacionais: análise da lista que prevê seu conteúdo proposicional pela teoria dos atos de fala. 2001. 166 p. Tese (Doutorado em Educação) - Universidade de São Paulo, 2001. 
TUGENDHAT, Ernst. Lições sobre ética. Petrópolis: Vozes, 1997.

UNESCO. Educação, um tesouro a descobrir: relatório para a Unesco da Comissão de Educação para o Século XXI. 1996. Disponível em: $<$ http://www.microeducacao.com.br/concurso/ConcursoPEBII2009/BDelors-Educacao-Um\%20Tesouro\%20a\%20Descobrir.pdf>. Acesso em: 15 jun. 2011.

Renato José de Oliveira, doutor em Educação pela Pontifícia Universidade Católica do Rio de Janeiro (PUC-RJ), é professor associado do Departamento de Fundamentos da Educação da Faculdade de Educação da UFRJ e do Programa de Pós-Graduação em Educação da mesma instituição (PPGE/UFRJ).

rj-oliveira1958@uol.com.br

Andrea Penteado de Menezes, doutora em Educação pela Universidade Federal do Rio de Janeiro (UFRJ), é professora adjunta do Departamento de Didática da Faculdade de Educação da UFRJ.

andrea.penteado@terra.com.br

Cristina Nacif Alves, doutora em Educação pela Universidade Federal do Rio de Janeiro (UFRJ), é coordenadora de Ensino da Fundação Getúlio Vargas (FGV) - Direito/RJ.

cristinalves@webcorner.com.br

Daniela Patti do Amaral, doutora em Educação pela Universidade Federal do Rio de Janeiro (UFRJ), é professora adjunta do Departamento de Administração Escolar da Faculdade de Educação da UFRJ.

danielapatti.ufrj@gmail.com

Recebido em 8 de julho de 2011.

Aprovado em 7 de novembro de 2012. 


\section{ANEXO 1 \\ Questionário Aplicado}

I - Informações Gerais: Idade Sexo: () M ( ) F Ano () $8^{\circ}$ ( ) $9^{\circ}$

1. Com que pessoas ou parentes você mora?

2. Levando em conta a renda dos seus responsáveis, você se considera: ( ) rico ( ) nem rico nem pobre ( ) pobre

3. Qual o seu tipo de diversão favorita?

II - Responda às questões que se seguem:

1. O que você entende por ética?

2. Marque com um X os enunciados que considerar éticos:

( ) roubar um alimento para não morrer de fome.

( ) mentir para salvar um homem condenado injustamente à morte.

( ) roubar um remédio para salvar a vida de um parente doente.

( ) não dar informações corretas ao professor para evitar que ele puna um colega de classe.

( ) nenhum dos enunciados acima.

3. O que você acha mais importante: fazer uma coisa boa ou fazer uma coisa útil? Por quê?

4. Escreva abaixo três palavras que considere ligadas à ética:

4.1) Dentre as palavras que você escreveu, quais ouve com mais frequência na escola?

Outras (diga quais)

4.2) Explique o que você entende sobre as palavras que escreveu: $1^{\mathrm{a}}$ palavra

$2^{\mathrm{a}}$ palavra

$3^{\mathrm{a}}$ palavra

4.3) Dê exemplos de situações que você vê ocorrer em sua casa e que se acham relacionadas a cada uma dessas palavras:

$1^{\mathrm{a}}$. palavra

$2^{\mathrm{a}}$. palavra

$3^{\mathrm{a}}$. palavra

4.4) Essas palavras têm contribuído para mudanças em sua vida? Dê exemplos. 
ANEXO 2

\section{Conjunto de Respostas dadas à Questão 1}

Orador 1: ser educado, respeitar os princípios, ter educação.

Orador 2: respeitar o próximo, se comportar, ser educado com os mais velhos.

Orador 3: é saber se comportar onde você estiver.

Orador 4: é respeitar os princípios e ser educado.

Orador 5: para mim, todos precisam ter ética, saber se comportar.

Orador 6: ético é ser responsável.

Orador 7: uma pessoa que convive com várias pessoas.

Orador 8: na escola onde estudo, têm uns professores que educam bem e outros não.

Orador 9: educação, respeito, a maneira correta de se comportar.

Orador 10: é educação, respeito, ensino, gentil.

Orador 11: educação.

Orador 12: ética é uma forma de expressar a educação, demonstrar sua dignidade.

Orador 13: ser educado.

Orador 14: é uma pessoa ser educada.

Orador 15: nada.

Orador 16: saber se comportar bem na sociedade.

Orador 17: é uma pessoa que converse com várias pessoas dependendo de sua cor e criatura.

Orador 18: na escola em que estudo têm algumas pessoas mal educadas.

Orador 19: quase nada. Ser educado.

Orador 20: ética é ter educação e respeito.

Orador 21: ética é ter educação, ser você mesma.

Orador 22: saber comportar-se devidamente.

Orador 23: em branco

Orador 24: A educação usada não só em casa, mas também no seu dia a dia, respeitando seus princípios.

Orador 25: saber se comportar em todos os lugares.

Orador 26: em branco

Orador 27: É ser você mesma com atitude e respeito.

Orador 28: é saber ser educado.

Orador 29: saber se comportar bem em todos os lugares. 
Orador 30: é a pessoa ter um bom caráter, ser educado.

Orador 31: eu acho que ética é uma pessoa com caráter, respeito e digna.

Orador 32: respeito ao próximo.

Orador 33: ter educação respeito um pelo outro.

Orador 34: não sei responder sobre isso.

Orador 35: educação, tratar direito as pessoas com respeito.

Orador 36: ser educado e saber seus momentos (fazer cada coisa e seu momento).

Orador 37: ética é ter atitude, educação e respeito.

Orador 38: nada, não entendi.

Orador 39: é uma pessoa mal educada ou uma pessoa imoral.

Orador 40: uma pessoa ética pra mim é uma pessoa de "princípios" que leva a educação dos pais adiante na vida.

Orador 41: pessoas que têm educação sabe se comportar.

Orador 42: a pessoa ser educada com moralidade etc.

Orador 43: como ser legal e respeitoso.

Orador 44: ser culta, saber se impor, se comportar e falar bem.

Orador 45: ser educado, respeitar todos, dar atenção aos outros, ajudar.

Orador 46: é ter educação na vida, em casa, no trabalho e na escola.

Orador 47: uma pessoa educada, sincera, gentil, respeitosa, ajudar os outros é uma boa pessoa.

Orador 48: pessoas com cultura, sabedoria e educação.

Orador 49: ser educado e ter cultura.

Orador 50: é saber ter respeito, disciplina e educação.

Orador 51: ser educado.

Orador 52: é uma pessoa muito educada.

Orador 53: ética é uma coisa que se vê se a pessoa é educada.

Orador 54: é não ter responsabilidade, sem educação, sem moral, etc.

Orador 55: nem sei o que é, mas acho que é não ter educação.

Orador 56: ter educação, ter respeito com todos, ter moral.

Orador 57: só entendo um pouco mais não sei explicar.

Orador 58: é ser educado, ter uma moral, respeito, civilidade.

Orador 59: ter educação, ter respeito com os outros.

Orador 60: é uma pessoa educada e solidária com todos.

Orador 61: ser bem educado.

Orador 62: é falta de educação (não ser ético).

Orador 63: nunca ouvi esta palavra.

Orador 64: educação, respeito. 